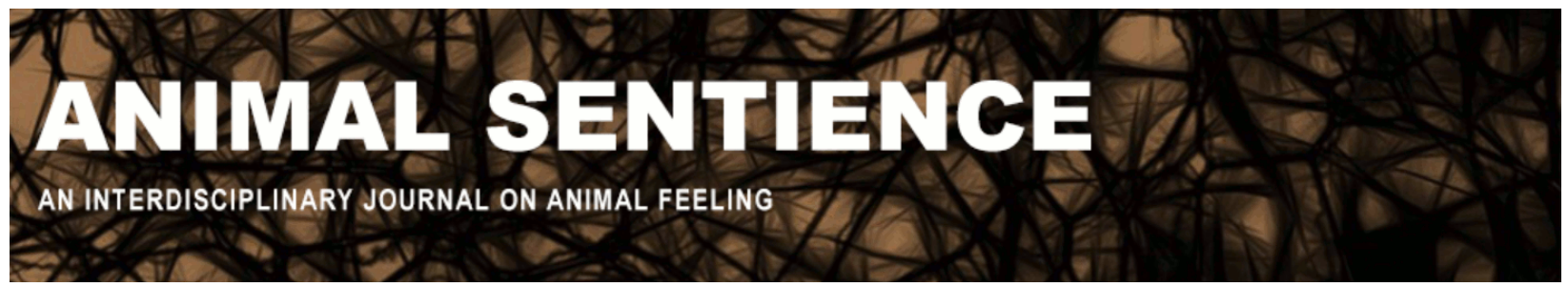

Gamez, David (2018) Fish consciousness. Animal Sentience 13(17)

DOI: $10.51291 / 2377-7478.1352$

Date of submission: $2018-06-20$

Date of acceptance: 2018-06-26

(c) (i)

This article has appeared in the journal Animal

Sentience, a peer-reviewed journal on animal

cognition and feeling. It has been made open access,

free for all, by WellBeing International and deposited

in the WBI Studies Repository. For more information,

please contact

wbisr-info@wellbeingintl.org.

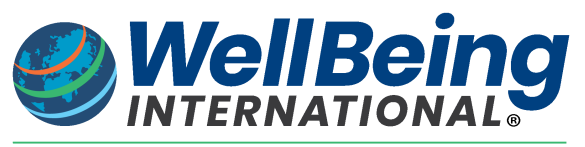

SOLUTIONS FOR PEOPLE, ANIMALS AND ENVIRONMENT 


\title{
Fish consciousness
}

Commentary on Woodruff on Fish Feel

\author{
David Gamez \\ Department of Computer Science \\ Middlesex University, UK
}

\begin{abstract}
Woodruff makes two arguments to support his claim that ray-finned fish are conscious: (1) Fish neuroanatomy has similarities with the structures in the human brain that support consciousness. (2) The complexity and flexibility of fish behaviour suggest that they are conscious. This commentary will argue that neither the neuroanatomical nor the behavioural argument can provide conclusive evidence for consciousness in fish. We should suspend judgement until we have discovered mathematical theories of consciousness that can reliably map between states of consciousness and states of the physical world.
\end{abstract}

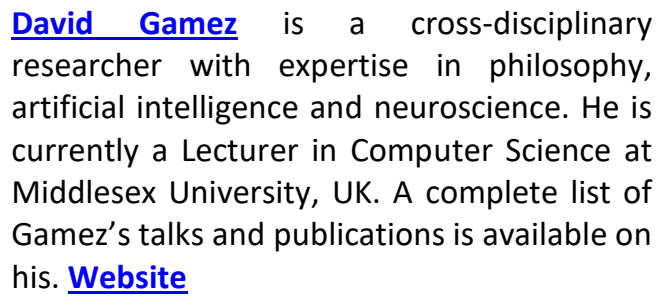

David Gamez is a cross-disciplinary researcher with expertise in philosophy, artificial intelligence and neuroscience. He is currently a Lecturer in Computer Science at Middlesex University, UK. A complete list of his. Website

A large part of Woodruff's (2017) target article is devoted to detailed comparisons between fish and human neuroanatomy. He suggests that fish are likely to be conscious because their brains implement many of the proposed correlates of consciousness in humans, such as sensorimotor integration, re-entrance, attention, emotions and neural synchronization.

One problem with this neuroanatomical argument is that the theories of consciousness which it is based on are mostly speculative, unproven and out of date. Consciousness has often been linked to higher functions such as attention that operate across multiple brain areas. Early work on the neural correlates of consciousness appeared to support this connection (Tononi and Koch 2008). However, more recent experiments have suggested that what was measured in these early experiments was not the correlates of consciousness but the correlates of reporting. It now appears that the correlates of consciousness are limited to a posterior cortical hot zone (Koch et al. 2016). If this turns out to be correct, then we should look for hot zones in the fish brain, not for re-entrant connections, emotions or attention.

A second problem with the theories of consciousness that Woodruff discusses is that they are mostly functional criteria for consciousness. A system is claimed to be conscious if it carries out sensorimotor integration, has re-entrant connections, emotions, attention and so on. However, functional theories of consciousness are extremely problematic. A function can be implemented in many different ways, and it is possible to map a function with a fixed set of input parameters onto any sequence of physical states (Bishop 2009; Putnam 1988). If we can attribute consciousness to fish on the basis of the functions that their brains implement, then consciousness can also be attributed to a computer program or lookup tables that implement the same functions (Block 2006). I have argued elsewhere that functional theories of consciousness are implausible and unworkable (Gamez 2018). The correlates of consciousness in humans are not likely to be a set of functions that could be implemented by 
a few lines of computer code. They are functions that are implemented in a particular way in biological neurons. The method of implementation of the function is as important as the function itself. We do not know how these functions are implemented in humans, so it is impossible to judge whether they are implemented in a similar way in fish.

In the absence of reliable knowledge about the neural correlates of consciousness in humans, the neuroanatomical argument boils down to the claim that fish brains are similar to human brains. It is possible that they contain the neural correlates of consciousness (whatever they turn out to be). However, fish brains are different from human brains, so it is also possible that their complex flexible behaviours are implemented in ways that are not correlated with consciousness. No clear conclusions can be drawn based on the current anatomical evidence (Tashereau-Dumouchel et al. 2017).

Woodruff also discusses some flexible complex behaviours that are associated with consciousness in humans, such as imitative learning, declarative memory and transitive inference. Consciousness appears to be necessary for these behaviours in humans, and they are also exhibited by fish. Suppose we could demonstrate that there was a reliable connection between consciousness and certain external behaviours: these might be termed the behavioural correlates of consciousness. In this case, we might be able to reliably infer the presence of consciousness from the system's external behaviour. If $X$ was a behavioural correlate of consciousness and the system exhibited behaviour $X$, then we would conclude that this system was conscious. We use this type of inference all the time when making inferences about consciousness in humans.

However, there is no evidence to suggest that a behaviour that is correlated with human consciousness is correlated with consciousness wherever it occurs. A human that opens its eyes and responds to commands is likely to be conscious; a robot that opens its eyes and responds to commands is unlikely to be conscious. As I discussed earlier, there are multiple ways of realizing the functions that produce behaviour. A body that performs a given set of actions can be controlled by biological neurons, silicon neurons, computer code, a giant lookup table, or the population of China communicating with radios and satellites (Block 2006). Putnam (1988) and Bishop (2009) have shown how any sequence of physical states can be mapped onto a function that produces a given behaviour. If consciousness can be inferred from behaviour alone, then it can be found everywhere - fish consciousness becomes a trivial consequence of an implausible panpsychism.

I have argued elsewhere that the science of consciousness should aim to discover mathematical theories of consciousness that can provide a fine-grained mapping between physical and conscious states (Gamez 2018). ${ }^{1}$ These mathematical theories can be discovered through experiments on humans and primates, who are typically assumed to be conscious. Once we have discovered a reliable mathematical theory of consciousness, we can use it to make believable predictions about fish consciousness. We can measure the state of a fish's brain and then use the mathematical theory to transform this physical measurement into a prediction about the consciousness of the fish. This is the correct scientific way of addressing questions about consciousness in fish.

\footnotetext{
${ }^{1}$ A number of mathematical theories of consciousness have been put forward. The best known is Tononi's (2008) information integration theory. This is a mathematical algorithm, which takes as its input a state transition of a physical system and outputs a prediction about the parts of the system that are conscious, the amount of consciousness that is present and a high-dimensional structure that purports to be a description of the state of consciousness. This theory has many limitations, but it is a good example of the type of theory that the science of consciousness should be looking for.
} 
Unfortunately, scientific work in this area is limited by the lack of high resolution data from the brain, and there are challenging problems with the measurement and description of consciousness. We are a long way from discovering mathematical theories that could provide definitive answers about fish consciousness. Although Woodruff's target article does not provide much evidence to suggest that fish are conscious, it does offer a strong counterargument to people who claim that fish are definitely not conscious. For the moment, we should suspend judgement about fish consciousness and treat fish in the same way as other sentient beings.

\section{References}

Bishop, J. M. (2009). A cognitive computation fallacy? Cognition, computations and panpsychism. Cognitive Computation 1: 221-33.

Block, N. (2006). Troubles with Functionalism. In Theories of Mind: An Introductory Reader, edited by M. Eckert. Maryland: Rowman \& Littlefield, pp. 97-102.

Gamez, D. (2018). Human and Machine Consciousness. Cambridge, MA: Open Book Publishers.

Koch, C., Massimini, M., Boly, M. and Tononi, G. (2016). Neural correlates of consciousness: Progress and problems. Nature Reviews Neuroscience 17(5): 307-21.

Putnam, H. (1988). Representation and Reality. Cambridge, MA: London: MIT Press.

Tashereau-Dumouchel, V., Grimaldi, P. and Lau, H. (2017). Can unconscious brain processes indicate sentience?. Animal Sentience 15(13).

Tononi, G. (2008). Consciousness as integrated information: A provisional manifesto. Biological Bulletin 215(3): 216-42.

Tononi, G. and Koch, C. (2008). The neural correlates of consciousness: An update. Annals of the New York Academy of Sciences 1124: 239-61.

Woodruff, M. L. (2017). Consciousness in teleosts: There is something it feels like to be a fish. Animal Sentience 13(1). 


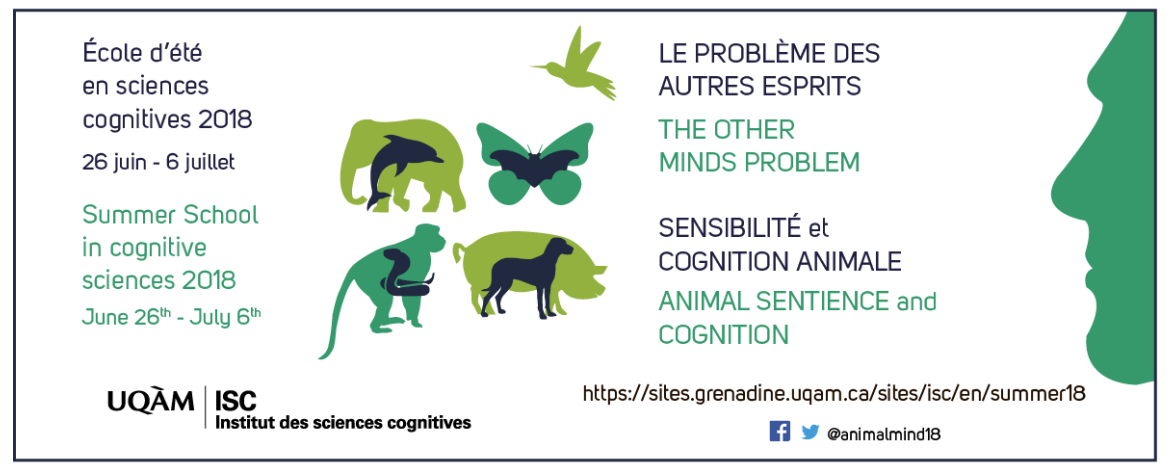

ISC 2018 Summer School in Cognitive Sciences

\author{
June 26 - July 6, 2018 \\ Montreal (Canada) \\ The Other Minds Problem: \\ Animal Sentience and \\ $\underline{\text { Cognition }}$
}

\begin{abstract}
Overview. Since Descartes, philosophers know there is no way to know for sure what - or whether - others feel (not even if they tell you). Science, however, is not about certainty but about probability and evidence. The 7.5 billion individual members of the human species can tell us what they are feeling. But there are 9 million other species on the planet (20 quintillion individuals), from elephants to jellyfish, with which humans share biological and cognitive ancestry, but not one other species can speak: Which of them can feel - and what do they feel? Their human spokespersons the comparative psychologists, ethologists, evolutionists, and cognitive neurobiologists who are the world's leading experts in "mind-reading" other species - will provide a sweeping panorama of what it feels like to be an elephant, ape, whale, cow, pig, dog, chicken, bat, fish, lizard, lobster, snail: This growing body of facts about nonhuman sentience has profound implications not only for our understanding of human cognition, but for our treatment of other sentient species
\end{abstract}

Gregory Berns: Decoding the Dog's Mind with Awake Neuroimaging Gordon Burghardt: Probing the Umwelt of Reptiles Jon Sakata: Audience Effects on Communication Signals

PANEL 1: Reptiles, Birds and Mammals

WORKSHOP 1: Kristin Andrews: The "Other" Problems: Mind,

Behavior, and Agency

Sarah Brosnan: How Do Primates Feel About Their Social Partners?

Alexander Ophir: The Cognitive Ecology of Monogamy

Michael Hendricks: Integrating Action and Perception in a Small

Nervous System

PANEL 2: Primates, Voles and Worms

WORKSHOP 2: Jonathan Birch: Animal Sentience and the

Precautionary Principle

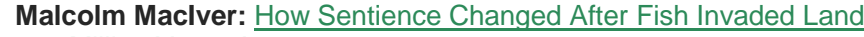

385 Million Years Ago

Sarah Woolley: Neural Mechanisms of Preference in Female

Songbird

Simon Reader: Animal Social Learning: Implications for

Understanding Others

PANEL 3: Sea to Land to Air

WORKSHOP 3: Steven M. Wise: Nonhuman Personhood

Tomoko Ohyama: Action Selection in a Small Brain (Drosophila

Maggot)

Mike Ryan: "Crazy Love": Nonlinearity and Irrationality in Mate Choice

Louis Lefebvre: Animal Innovation: From Ecology to

Neurotransmitters

PANEL 4: Maggots, Frogs and Birds: Flexibility Evolving

SPECIAL EVENT: Mario Cyr: Polar Bears

Colin Chapman: Why Do We Want to Think People Are Different?

Vladimir Pradosudov: Chickadee Spatial Cognition

Jonathan Balcombe: The Sentient World of Fishes

PANEL 5: Similarities and Differences

WORKSHOP 5 (part 1): Gary Comstock: A Cow's Concept of Her

Future

WORKSHOP 5 (part 2): Jean-Jacques Kona-Boun: Physical and

Mental Risks to Cattle and Horses in Rodeos
Joshua Plotnik: Thoughtful Trunks: Application of Elephant Cognition for Elephant Conservation

Lori Marino: Who Are Dolphins?

Larry Young: The Neurobiology of Social Bonding, Empathy and Social Loss in Monogamous Voles

Panel 6: Mammals All, Great and Small

WORKSHOP 6: Lori Marino: The Inconvenient Truth About Thinking

Chickens

Frantisek Baluska \& Stefano Mancuso: What a Plant Knows and Perceives

Arthur Reber: A Novel Theory of the Origin of Mind: Conversations

With a Caterpillar and a Bacterium

PANEL 7: Microbes, Molds and Plants

WORKSHOP 7: Suzanne Held \& Michael Mendl: Pig Cognition and

Why It Matters

James Simmons: What Is It Like To Be A Bat?

Debbie Kelly: Spatial Cognition in Food-Storing

Steve Phelps: Social Cognition Across Species

PANEL 8: Social Space

WORKSHOP 8: To be announced

Lars Chittka: The Mind of the Bee

Reuven Dukas: Insect Emotions: Mechanisms and Evolutionary

Biology

Adam Shriver: Do Human Lesion Studies Tell Us the Cortex is

Required for Pain Experiences?

PANEL 9: The Invertebrate Mind

WORKSHOP 9: Delcianna Winders: Nonhuman Animals in Sport and Entertainment

Carel ten Cate: Avian Capacity for Categorization and Abstraction Jennifer Mather: Do Squid Have a Sense of Self?

Steve Chang: Neurobiology of Monkeys Thinking About Other

Monkeys

PANEL 10: Others in Mind

WORKSHOP 10: The Legal Status of Sentient Nonhuman Species 